\title{
Tapered-tip Teflon catheter: another device for sequential dilation in endoscopic ultrasound- guided hepaticogastrostomy
}

We report the case of a 54-year-old man who had previously undergone a gastrojejunostomy due to a perforated gastric ulcer. He developed hilar cholangiocarcinoma and underwent endoscopic retrograde cholangiopancreatography (ERCP),

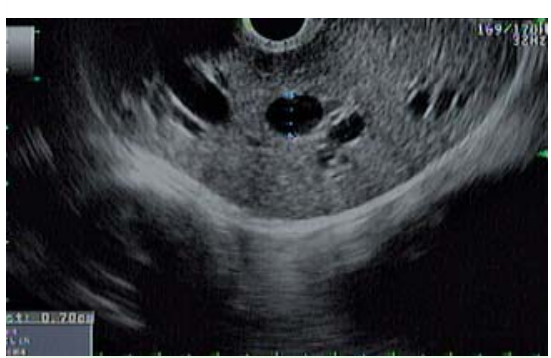

Fig. 1 Echo endoscopic image of the dilated left intrahepatic bile duct.

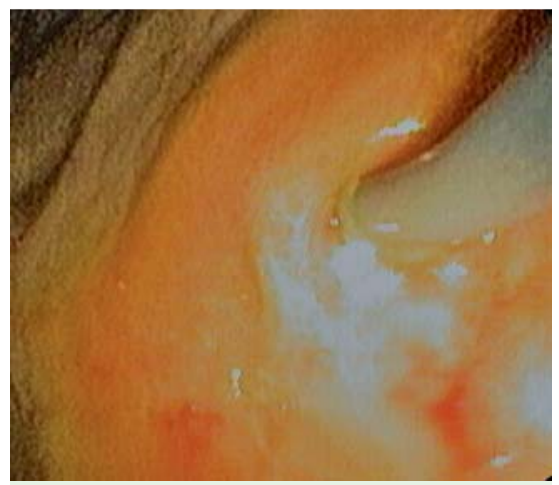

Fig. 2 Endoscopic view during dilation of the hepaticogastrostomy tract with a tapered-tip Teflon catheter. but duodenal intubation failed because of his surgically altered anatomy. He was therefore scheduled to undergo biliary drainage by endoscopic ultrasound (EUS)-guided hepaticogastrostomy using a therapeutic curved linear echo endoscope (GF-UC 140P; Olympus, Tokyo, Japan).

The EUS revealed marked dilation of both intrahepatic bile ducts ( $\bullet$ Fig. 1).

After the left intrahepatic bile duct was located using the echo endoscope in a short position, the dilated peripheral ductal branch closest to the transducer was punctured transgastrically using a 19-gauge fine needle aspiration (FNA) needle. After bile had been aspirated and contrast had been injected to visualize the duct, a 0.035-inch jag wire was inserted through the FNA needle and positioned deep within the proximal duct. The tract between the stomach and the left intrahepatic bile duct was then sequentially dilated using 7-Fr up to 10-Fr tapered-tip Teflon catheters ( $\bullet$ Figs. 2 and $\mathbf{3}$ ).

Finally, a fully covered self-expandable metal stent (SEMS; Flare-type, $100 \mathrm{~mm} \times$ $80 \mathrm{~mm}$ BK1008F, with an 8.5-Fr introducer (TaeWoong Medical, Gyeonggi-do, South Korea) was successfully inserted through the hepaticogastrostomy tract into the intrahepatic bile duct with satisfactory drainage ( $\bullet$ Fig. 4 ).

The most important step in this procedure was dilation of the tract between the stomach and the intrahepatic bile duct. Most endoscopists use either an ERCP cannula, a 6- or 8.5-Fr cystotome, a 6-Fr bougie, or a 4- or 6-mm dilating balloon [1-4]. In this case, we planned to place a new flare-type SEMS with an 8.5-Fr introducer to prevent migration. From our experience, we prefer not to use the dilating balloon because of the possibility of serious complications such as bleeding, bile leakage, or perforation. Therefore, we made three sizes of tapered-tip Teflon catheters (7-, 8.5-, and 10-Fr; $\bullet$ Fig. 5).

This dilation method was not difficult, but required good positioning of the tip of the echo endoscope, which allowed for better handling of the scope and catheter. We believe this technique is another good option for dilation of a hepaticogastrostomy tract that is equally successful but possibly has fewer complications.

\section{Endoscopy_UCTN_Code_TTT_1AS_2AD}

\section{Competing interests: None}

\section{Prachayakul, P. Aswakul, U. Kachinthorn}

Endoscopy Center, Siriraj Hospital, Bangkok, Thailand

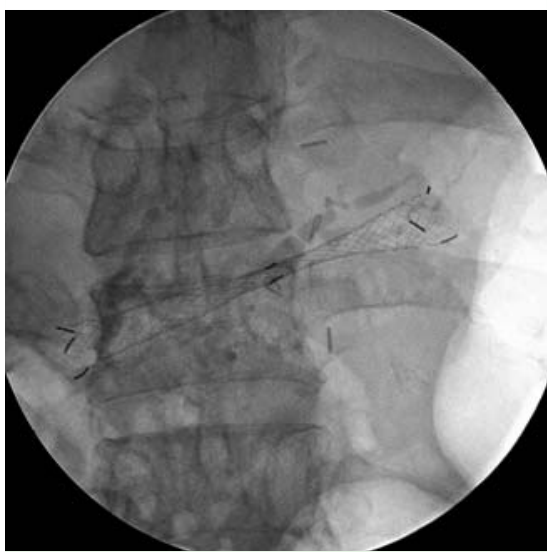

Fig. 4 Radiographic image after placement of a self-expandable metal stent (SEMS). 


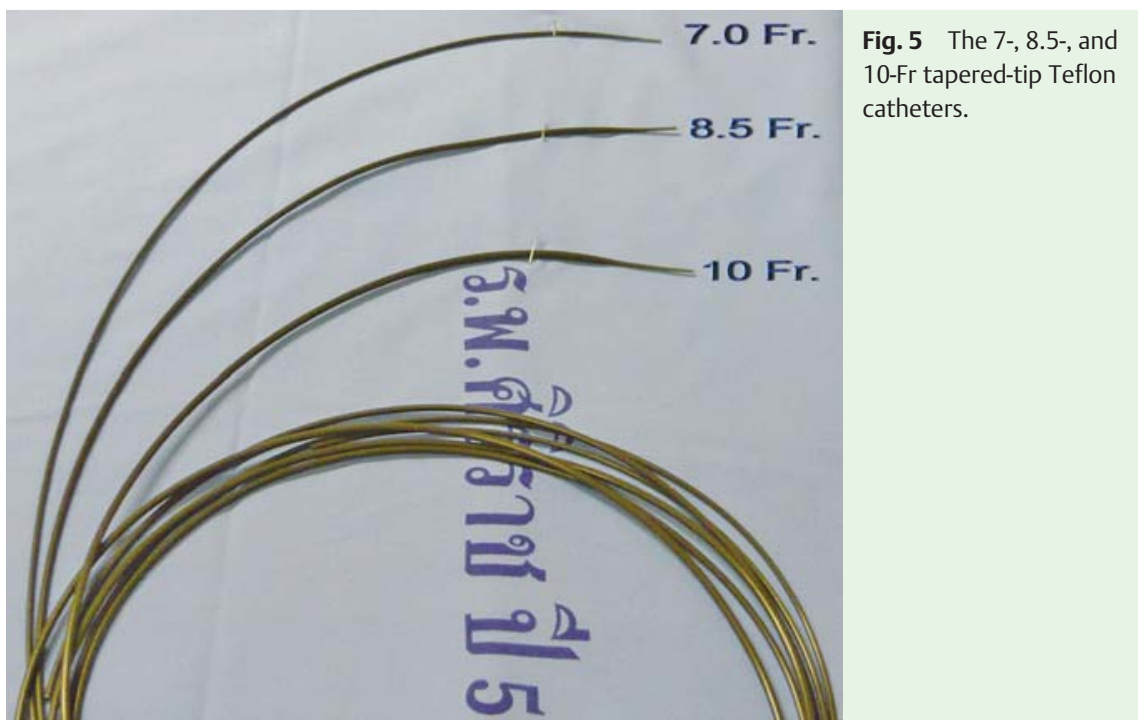

\section{References}

1 Itoi T, Sofuni A, Itokawa $F$ et al. Endoscopic ultrasonography-guided biliary drainage. J Hepatobiliary Pancreat Sci 2010; 17: 611 616

2 Park DH, Song TJ, Eum J et al. EUS-guided hepaticogastrostomy with a fully covered metal stent as the biliary diversion technique for an occluded biliary metal stent after failed ERCP (with videos). Gastrointest Endosc 2010; 17: 413-419

3 Savides TJ, Varadarajulu S, Palazzo L. EUS 2008 Working Group document: evaluation of EUS-guided hepaticogastrostomy. Gastrointest Endosc 2009; 69: S3-S7

\section{Bibliography}

DOI $10.1055 / \mathrm{s}-0030-1256395$

Endoscopy 2011; 43: E213-E214

(c) Georg Thieme Verlag KG Stuttgart · New York . ISSN 0013-726X

\section{Corresponding author V. Prachayakul, MD}

Siriraj Endoscopy Center

Siriraj Hospital - Internal medicine

Prannok Road

Bangkok 10700

Thailand

Fax: +66-2411-5013

psprvaks@gmail.com 